\title{
Pleiotropic Effects of Biguanides on Mitochondrial Reactive Oxygen Species Production
}

\author{
Alena Pecinova, Zdenek Drahota, Jana Kovalcikova, Nikola Kovarova, Petr Pecina, \\ Lukas Alan, Michal Zima, Josef Houstek, and Tomas Mracek
}

Institute of Physiology of the Czech Academy of Sciences, Vídeňská, 1083 Prague, Czech Republic

Correspondence should be addressed to Tomas Mracek; tomas.mracek@fgu.cas.cz

Received 29 March 2017; Accepted 13 June 2017; Published 9 August 2017

Academic Editor: Jacek Zielonka

Copyright $\odot 2017$ Alena Pecinova et al. This is an open access article distributed under the Creative Commons Attribution License, which permits unrestricted use, distribution, and reproduction in any medium, provided the original work is properly cited.

\begin{abstract}
Metformin is widely prescribed as a first-choice antihyperglycemic drug for treatment of type 2 diabetes mellitus, and recent epidemiological studies showed its utility also in cancer therapy. Although it is in use since the 1970s, its molecular target, either for antihyperglycemic or antineoplastic action, remains elusive. However, the body of the research on metformin effect oscillates around mitochondrial metabolism, including the function of oxidative phosphorylation (OXPHOS) apparatus. In this study, we focused on direct inhibitory mechanism of biguanides (metformin and phenformin) on OXPHOS complexes and its functional impact, using the model of isolated brown adipose tissue mitochondria. We demonstrate that biguanides nonspecifically target the activities of all respiratory chain dehydrogenases (mitochondrial NADH, succinate, and glycerophosphate dehydrogenases), but only at very high concentrations $\left(10^{-2}-10^{-1} \mathrm{M}\right)$ that highly exceed cellular concentrations observed during the treatment. In addition, these concentrations of biguanides also trigger burst of reactive oxygen species production which, in combination with pleiotropic OXPHOS inhibition, can be toxic for the organism. We conclude that the beneficial effect of biguanides should probably be associated with subtler mechanism, different from the generalized inhibition of the respiratory chain.
\end{abstract}

\section{Introduction}

Metformin (dimethyl biguanide) is the most widely used frontline drug for treatment of type II diabetes mellitus $[1,2]$. At the whole-body level, it effectively decreases blood glucose and insulin levels during hyperglycemia [3]. Several possible mechanisms of its action have been suggested, including inhibition of adenylate cyclase [4], interference with mitochondrial dynamics [5], alterations in gut microbiota composition [6], or inhibition of mitochondrial respiratory chain $[7,8]$. Some of the proposed mechanisms oscillate around AMP-activated protein kinase (AMPK) activation, which in itself was also suggested as a direct target for biguanides [5, 9]. However, precise molecular mechanism of its action remains questionable $[10,11]$.

Metformin utility was also explored in the model of heart failure where epidemiologic evidence suggests its protective effect $[12,13]$. Nevertheless, at the molecular level, a direct effect on mitochondria is observed in some cases [14], but not in others [15].

In addition to its antihyperglycemic effect, a broad range of epidemiologic studies showed that chronic metformin treatment is associated with a reduced risk of cancer [16-18]. As well as in the case of diabetes, the explicit mechanism of its antineoplastic action is not yet clear [11]. Metformin was proposed to act either indirectly by decreasing levels of insulin [19] or directly by suppression of mitochondrial-dependent biosynthetic pathways $[20,21]$. One of the most studied possible molecular targets for biguanides action is their inhibitory action on respiratory chain complex I (NADH dehydrogenase, NDH), first described in liver tissue $[8,22]$. Since then, it was confirmed for various tissues and cellular models and crucially also for cancer cells [11, 23, 24]. Hypothetical model proposes that $\mathrm{NDH}$ inhibition leads to decreased respiration and consequently to activation of AMPK, the key player in cellular 
energy homeostasis [25]. The exact site of biguanide binding to $\mathrm{NDH}$ is ambiguous; it was found to influence reactivity of its flavin cofactor, but it also inhibits ubiquinone reduction in a noncompetitive manner [23]. In addition to $\mathrm{NDH}$, metformin was shown to inhibit other enzymes of the mitochondrial oxidative phosphorylation apparatus, including mitochondrial glycerophosphate dehydrogenase (mGPDH) and ATP synthase [7, 10, 23]. Interestingly, the viability of cancer cells lacking mitochondrial DNA (rho0 cells) is also affected by the drug, making its putative action on respiratory chain complexes rather questionable [26].

Respiratory chain is also a predominant source of reactive oxygen species (ROS), and targeting individual complexes may modulate ROS production and thus influence various pathological processes and/or signaling in different metabolic pathways [27]. Using specific substrates and inhibitors of respiratory chain enzymes, it is possible to localize the site of ROS generation or conversely the binding site of the inhibitor. In isolated mitochondria, the electron leak occurs mainly under the conditions of high $\mathrm{NAD}(\mathrm{P}) \mathrm{H}$ pool reduction $[28,29]$ or high ubiquinone pool reduction (high proton motive force) [29-31]. Essentially, all of the dehydrogenases in the respiratory chain were under certain conditions demonstrated to allow electron leak and ROS production. Flavin site of complex $\mathrm{I}_{\mathrm{F}}\left(\mathrm{I}_{\mathrm{F}}\right)$ was identified as a site of superoxide production using NADH-linked substrates $[32,33]$. Under the conditions of high flux from succinate oxidation and high proton motive force, the electrons can backflow to $\mathrm{NDH}$ and escape at the level of $\mathrm{Q}$ site $\left(\mathrm{I}_{\mathrm{Q}}\right)$ towards the molecular oxygen [30,31]. SDH itself was shown to produce significant amounts of ROS, especially when succinate levels are low (submillimolar). Under these conditions, flavin site $\left(\mathrm{II}_{\mathrm{F}}\right)$ is not fully occupied by the substrate and is more accessible to oxygen allowing superoxide generation [34]. Mitochondrial mGPDH was also shown to act as a potent ROS producer [35] even in mitochondria from tissues with low amount of the enzyme [36]. ROS production from mGPDH can reach the levels of ROS from complex III when inhibited with antimycin A (the most potent source of ROS in mitochondria) [37]. Since mGPDH-dependent ROS production increases linearly with increasing GP concentration, the most plausible site of electron leak is the Q site or the semiquinone formed here [27].

Given the conflicting reports regarding the molecular target of biguanides in mitochondria, in this study, we addressed the direct impact of biguanides metformin and phenformin on $\mathrm{NDH}, \mathrm{SDH}$, and $\mathrm{mGPDH}$, mitochondrial glycerophosphate dehydrogenases, which feed electrons into respiratory chain and were proposed to be a target of these drugs. We used mitochondria isolated from brown adipose tissue (BAT), which are advantageous for such study as they contain comparable amounts of these dehydrogenases. Furthermore, uncoupling protein 1 (UCP1) dissipates mitochondrial membrane potential $\left(\Delta \psi_{\mathrm{m}}\right)$ in the isolated BAT mitochondria so that the cationic biguanides are much less concentrated in mitochondrial matrix, and therefore, the determined concentrations of these drugs are very close to the actual ones required for inhibition. We compared the effects of biguanides on dehydrogenases with their typical inhibitors (rotenone, atpenin A5, and iGP-1) using activity assays, mitochondrial oxygen consumption, and ROS production.

\section{Materials and Methods}

2.1. Isolation of Mitochondria from Brown Adipose Tissue. We used interscapular brown adipose tissue (BAT) of fourweek-old Wistar rats kept at $22^{\circ} \mathrm{C}$ under $12 \mathrm{~h} / 12 \mathrm{~h}$ light/dark cycle on a standard diet and water supply ad libitum. All animal works were approved by the institutional ethics committee and were in accordance with the EU Directive 2010/63/EU for animal experiments. Mitochondria were isolated in STE medium $(250 \mathrm{mM}$ sucrose, $10 \mathrm{mM}$ Tris$\mathrm{HCl}, 1 \mathrm{mM}$ EDTA, $\mathrm{pH}$ 7.4) and supplemented with BSA $(10 \mathrm{mg} / \mathrm{mL})$ by differential centrifugation [38]. Quality of isolation was routinely checked by oxygraph, and fresh mitochondria were used for measurements of oxygen consumption and hydrogen peroxide production. Subsequently, frozen-thawed mitochondria were used for determination of enzymatic activities; as in such preparations, the integrity of mitochondrial membrane is disrupted and $\mathrm{NADH}$ has therefore access to the oxidation site of NDH. Also, freezing/thawing ensures that the membrane potential is not maintained.

2.2. Enzyme Activity Assays. Activities of mitochondrial dehydrogenases were determined spectrophotometrically as NADH oxidoreductases $(\mathrm{NDH}$, monitored at $340 \mathrm{~nm}$, $\varepsilon_{340}=6.22 \mathrm{mM}^{-1} \cdot \mathrm{cm}^{-1}$ ) or $\mathrm{CoQ}_{1}$ oxidoreductases (SDH and $\mathrm{mGPDH}$, monitored at $\left.275 \mathrm{~nm}, \varepsilon_{275}=13.6 \mathrm{mM}^{-1} \cdot \mathrm{cm}^{-1}\right)$. The assay medium contained $50 \mathrm{mM} \mathrm{KCl}, 20 \mathrm{mM}$ Tris$\mathrm{HCl}, 1 \mathrm{mM}$ EDTA, $1 \mathrm{mg} / \mathrm{mL}$ BSA, $2 \mathrm{mM} \mathrm{KCN}, \mathrm{pH} 7.4$, and $50 \mu \mathrm{M} \mathrm{CoQ}$. The reaction was started by adding $100 \mu \mathrm{M}$ $\mathrm{NADH}, 25 \mathrm{mM}$ glycerophosphate (GP), or $25 \mathrm{mM}$ succinate, respectively, and after 5-10 minutes, changes of absorbance were monitored at $30^{\circ} \mathrm{C}$. Enzyme activities were expressed as $\mathrm{pmol} / \mathrm{s} / \mathrm{mg}$ protein.

\subsection{Determination of Mitochondrial Membrane Potential.} The changes in mitochondrial membrane potential $\left(\Delta \psi_{\mathrm{m}}\right)$ were measured with $\mathrm{TPP}^{+}$-selective electrode as described in $[39,40]$. Isolated BAT mitochondria $(0.4 \mathrm{mg} / \mathrm{mL})$ were resuspended in $\mathrm{KCl}$ medium and subsequently supplemented with $10 \mathrm{mM}$ GP, $0.3 \%$ BSA, $1 \mathrm{mM}$ GDP, and $1 \mu \mathrm{M}$ carbonyl cyanide-p-trifluoromethoxyphenylhydrazone (FCCP). The electrode was calibrated by stepwise addition of $\mathrm{TPP}^{+}$ $(1-6 \mu \mathrm{M})$ before each measurement, and $\Delta \psi_{\mathrm{m}}$ changes were plotted as pTPP, that is, the negative common logarithm of $\mathrm{TPP}^{+}$concentration.

\subsection{Fluorometric Detection of Hydrogen Peroxide Production.} Hydrogen peroxide production was determined fluorometrically by measuring oxidation of Amplex UltraRed (Thermo Fisher) essentially as before [27]. Fluorescence of the Amplex UltraRed oxidation product was measured at $37^{\circ} \mathrm{C}$ using Tecan Infinite M200 multiwell fluorometer. Excitation/ emission wavelengths were $544 \mathrm{~nm}$ (bandwidth $15 \mathrm{~nm}$ )/ $590 \mathrm{~nm}$ (bandwidth $30 \mathrm{~nm}$ ). The assay was performed with $10 \mu \mathrm{g}$ of mitochondrial protein in KCl-based medium 
$\left(120 \mathrm{mM} \mathrm{KCl}, 3 \mathrm{mM}\right.$ HEPES, $5 \mathrm{mM} \mathrm{KH}_{2} \mathrm{PO}_{4}, 3 \mathrm{mM} \mathrm{MgSO}_{4}$, $1 \mathrm{mM}$ EGTA, $3 \mathrm{mg} / \mathrm{mL}$ BSA, pH 7.2) supplemented either with $10 \mathrm{mM}$ pyruvate plus $2 \mathrm{mM}$ malate, $10 \mathrm{mM}$ succinate, or $10 \mathrm{mM} \mathrm{GP}$. Amplex UltraRed was used at the final concentration of $50 \mu \mathrm{M}$ with horseradish peroxidase (HRP) at $1 \mathrm{U} / \mathrm{mL}$. Fluorescence signal from the well containing all substrates and inhibitors, but not mitochondria, was subtracted as a background for every experimental condition used. Background, caused mostly by autoxidation of the dye or nonenzymatic effect of inhibitors on apparent ROS production, varied between conditions from 0 to $1 \mathrm{pmol} / \mathrm{s} / \mathrm{mg}$ and was uniform across respective titration points. Signal was calibrated using $\mathrm{H}_{2} \mathrm{O}_{2}$ at the final concentration of $0-5 \mu \mathrm{M}$, and $\mathrm{H}_{2} \mathrm{O}_{2}$ stock concentration was routinely checked by measuring its absorption at $240 \mathrm{~nm}$.

2.5. Western Blotting. BAT and liver homogenates were denatured at $65^{\circ} \mathrm{C}$ for $15 \mathrm{~min}$ in a sample lysis buffer $(2 \%$ $(v / v)$ 2-mercaptoethanol, $4 \%(w / v)$ SDS, $50 \mathrm{mM}$ Tris- $\mathrm{HCl}$, $\mathrm{pH} 7.0,10 \%(v / v)$ glycerol, and $0.017 \%(w / v)$ Coomassie Brilliant Blue R-250), and Tricine SDS-PAGE [41] was performed on $10 \%(w / v)$ polyacrylamide slab gels at room temperature. The gels were blotted onto a PVDF membrane (Immobilon P, Merck Millipore) by semidry electrotransfer at $0.8 \mathrm{~mA} / \mathrm{cm}^{2}$ for $1 \mathrm{~h}$. Membranes were blocked in $5 \%$ nonfat dried milk dissolved in TBS $(150 \mathrm{mM} \mathrm{NaCl}, 10 \mathrm{mM}$ Tris$\mathrm{HCl}, \mathrm{pH} 7.5)$ for $1 \mathrm{~h}$ at room temperature and incubated for $2 \mathrm{~h}$ with the following primary antibodies: antibody to NADH dehydrogenase (NDUFA9 subunit of complex I)-Abcam ab14713, succinate dehydrogenase complex (subunit A (SDHA) of complex II)-Abcam ab14715, Core2 subunit of complex III-Abcam ab14745, actin-Millipore MAB1501, rabbit polyclonal antibody to porin $(1: 1000)$ was a kind gift from Professor Vito de Pinto (Dipartimento di Scienze Chimiche, Catania, Italy), and rabbit polyclonal antibody to mGPDH was custom prepared [42]. Membranes were then incubated for $1 \mathrm{~h}$ with corresponding secondary fluorescent antibodies, IRDye 680- or 800-conjugated donkey anti-mouse IgG (Thermo Fischer) or donkey antirabbit IgG (LI-COR Biosciences), respectively. The fluorescence was detected using ODYSSEY infra-red imaging system (LI-COR Biosciences), and the signal was quantified using Aida 3.21 Image Analyzer software (RayTest).

2.6. Polarographic Detection of Oxygen Consumption. Oxygen consumption was measured at $30^{\circ} \mathrm{C}$ as described before [35] using Oxygraph-2k (Oroboros, Austria). Measurements were performed in $2 \mathrm{~mL}$ of $\mathrm{KCl}$ medium $(80 \mathrm{mM}$ $\mathrm{KCl}, 10 \mathrm{mM}$ Tris- $\mathrm{HCl}, 3 \mathrm{mM} \mathrm{MgCl}_{2}, 1 \mathrm{mM}$ EDTA, $5 \mathrm{mM}$ $\mathrm{K}-\mathrm{Pi}, \mathrm{pH}$ 7.4) using $15-60 \mu \mathrm{g}$ protein/mL of freshly isolated mitochondria. For measurements, $10 \mathrm{mM}$ pyruvate plus $2 \mathrm{mM}$ malate, $10 \mathrm{mM}$ succinate, or $10 \mathrm{mM} \mathrm{GP}$, respectively, were used. The oxygen consumption was expressed in pmol oxygen/s/mg protein.

\section{Results and Discussion}

The direct mechanistic knowledge on how biguanides (metformin, phenformin) influence mitochondrial function is not yet clear. While their inhibitory effect on NADH dehydrogenase (complex I, NDH) received most attention $[8,23,24]$, it was also reported that biguanides can inhibit other dehydrogenases in the mitochondrial respiratory chain, namely, succinate dehydrogenase (SDH) [10] and mitochondrial glycerophosphate dehydrogenase (mGPDH) [7]. As those dehydrogenases substantially differ in their architecture of substrate sites, coenzyme Q (CoQ), binding sites and pathways of the electron transfer from substrate to $\mathrm{CoQ}$, such as lack of selectivity, is rather surprising. Therefore, we focused on the action of biguanides on $\mathrm{NDH}$, $\mathrm{SDH}$, and $\mathrm{mGPDH}$ and compared it with canonical specific inhibitors of ubiquinone binding site of complex I (rotenone) [31], ubiquinone site of SDH (atpenin A5) [43], and the novel specific inhibitor of mGPDH (iGP-1) [44].

As a model, we chose isolated mitochondria from brown adipose tissue (BAT), as they have several advantages for such study. First, compared to the liver, where the inhibitory action of biguanides on mGPDH was originally described [7], they contain near equimolar levels of all three dehydrogenases studied. This can be documented both at the level of protein quantity (Figure 1(a)) and enzyme activity (NDH, SDH, and mGPDH, Figure 1(b)). The differences in response between dehydrogenases in BAT cannot therefore be ascribed to the varying content of enzymes studied. It is well established [36] and also obvious from Figure 1(b) that mGPDH activity in the liver is particularly low, and this can render the accurate measurement of inhibitory effects on GQR quite difficult. Another advantage of BAT mitochondria is the presence of UCP1 protein [45] which under native conditions allows the flow of protons back to the matrix (Figure 1(c)) and thus effectively discharges the mitochondrial membrane potential to the same level as prototypic uncoupler FCCP as can be seen by direct $\Delta \psi_{\mathrm{m}}$ determination on $\mathrm{TPP}^{+}$-selective electrode (Figure $1(\mathrm{~d})$ ). This means that studied ROS production is independent of OXPHOS coupling. On the other hand, mitochondria can easily be coupled by the inhibitory action of guanosine diphosphate (GDP) on the UCP1 and contribution of electron backflow can then be established. Finally, lack of coupling together with physiologically low levels of mitochondrial $\mathrm{F}_{\mathrm{o}} \mathrm{F}_{1}$ ATP synthase makes the action of biguanides on mitochondrial dehydrogenases rather independent of ATP synthase activity. This is quite important as $\mathrm{F}_{\mathrm{o}} \mathrm{F}_{1}$ ATP synthase was also shown to be inhibited by biguanides [23] and thus may blur the picture in other model systems.

3.1. Effect of Biguanides on Enzymatic Activities. As a first step, we estimated direct impact of metformin on activity of each complex measured as individual dehydrogenase activity (substrate: coenzyme Q) in frozen-thawed mitochondria or in the context of electron transport chain in intact mitochondria measured as oxygen consumption using respective substrates (Figure 2). Metformin inhibited all enzymes studied, but only at very high concentrations $\left(\mathrm{IC}_{50}\right.$ varied from 80 to $180 \mathrm{mM}$, Figures 2(a), 2(b), and 2(c)). Out of those activities, NDH was the most sensitive to the inhibitory action of metformin (Figure 2(a)). Similarly, at the same concentrations, metformin also inhibited respiration with pyruvate 


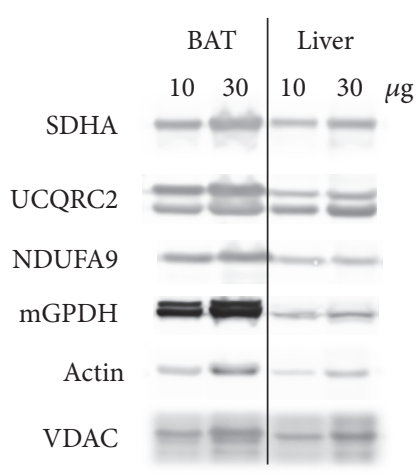

(a)

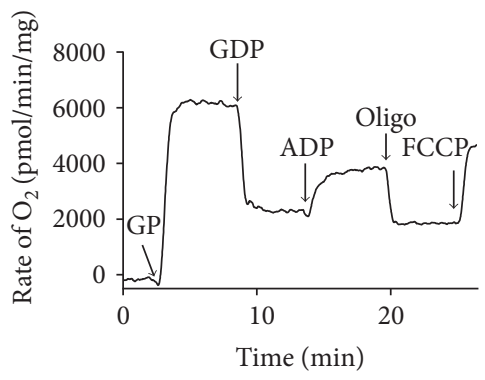

(c)

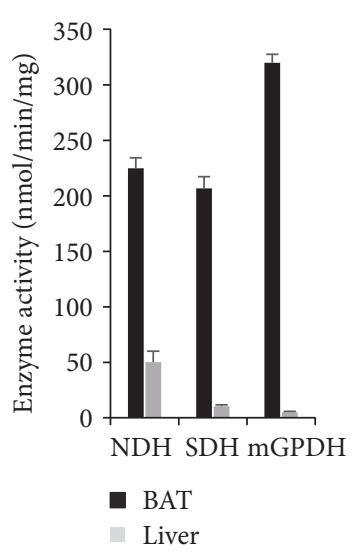

(b)

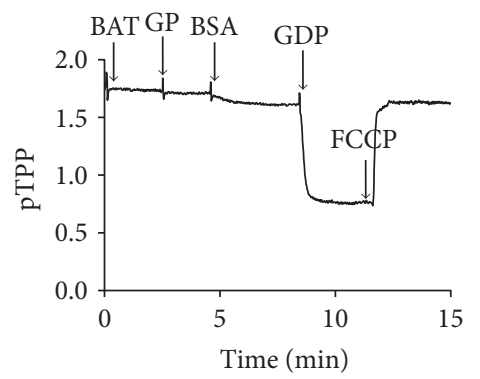

(d)

FIGURE 1: Characterization of brown adipose tissue (BAT) mitochondria. (a) SDS-PAGE and Western blot analysis of mitochondrial respiratory chain complexes in BAT and liver homogenates by polyclonal antibodies against mGPDH and VDAC and monoclonal antibodies against representative subunits of NDH (subunit NDUFA9), SDH (subunit SDHA), complex III (subunit UCQRC2), and actin. Two protein concentrations were loaded as indicated, representative image of three biological replicates. (b) Enzyme activities of mitochondrial dehydrogenases in mitochondria isolated from the $\mathrm{BAT}$ and liver. Activities were determined as rates of $\mathrm{CoQ}_{1}$ reduction using respective substrates. Results are means \pm SEM from three independent measurements. (c) Representative quality control curve of $\mathrm{O}_{2}$ consumption and (d) representative trace of $\Delta \psi_{\mathrm{m}}$ measurement in isolated BAT mitochondria. The following compounds were added: $10 \mathrm{mM}$ glycerophosphate (GP), 0.3\% BSA, $1 \mathrm{mM}$ GDP, $1 \mathrm{mM}$ ADP, $1 \mu \mathrm{M}$ oligomycin (oligo), and $1 \mu \mathrm{M}$ carbonyl cyanide-p-trifluoromethoxyphenylhydrazone (FCCP).

and malate used as substrates for NDH (Figure 2(d)), succinate for SDH (Figure 2(e)), and glycerophosphate (GP) for mGPDH (Figure 2(f)). Another biguanide, phenformin, behaved analogously to metformin, but its inhibitory effect was more efficient; the $\mathrm{IC}_{50}$ varied between 10 and $25 \mathrm{mM}$ for both isolated enzyme activities and respiration of all three dehydrogenases (Figure 3). Because of the limited permeability of the biguanides, we waited to reach plateau (approximately $5 \mathrm{~min}$ ) before proceeding to the next addition. It is to be stressed that $\mathrm{IC}_{50}$ values of observed inhibitory effects in uncoupled mitochondria (oxygraphy) were the same or slightly higher than corresponding $\mathrm{IC}_{50}$ values in frozen-thawed mitochondria (spectrophotometry), thus conferring comparable concentration of biguanides on both sides of the inner mitochondrial membrane. Determined $\mathrm{IC}_{50}$ in our case is rather high in comparison with that previously reported $[7,33]$. This can be most likely attributed to the uncoupled state of BAT mitochondria which prevents accumulation of biguanides in mitochondria (see below).

Subsequently, we focused on the action of canonical inhibitors on individual complexes. As expected, rotenone completely inhibited complex I enzyme activity as well as pyruvate plus malate-supported oxygen consumption at $500 \mathrm{nM}$. Similarly, complete inhibition of SDH by atpenin A5 using succinate as a substrate was achieved at even lower concentrations $(20 \mathrm{nM})$ and activity of mGPDH was abolished at $50 \mu \mathrm{M}$ of iGP-1. Interestingly, we also observed some nonspecific actions of iGP-1 on SDH (Figures 4(b) and 4(d)), but the $\mathrm{IC}_{50}$ was significantly higher $(\sim 80 \mu \mathrm{M})$ than that in the case of mGPDH (Figures 4(a) and 4(c)).

Given the extremely high $\mathrm{IC}_{50}$ we identified for phenformin and metformin, it is to be questioned whether their effects on respiratory chain enzymes are pharmacologically relevant and can affect mitochondrial function in tumors. As already mentioned, isolated BAT mitochondria with inherently low levels of mitochondrial membrane potential represent a model free of the effect of metformin partitioning due to its charge. Biguanides carry a positive charge, which means that they do accumulate in cells and mitochondria in dependence on membrane potential across both cellular and mitochondrial membranes. Thus, the concentration could be 100 to 300 times higher inside energized mitochondria (compared to concentration in cytosol) with the difference in mitochondrial membrane potential between 




(a) Specific activity

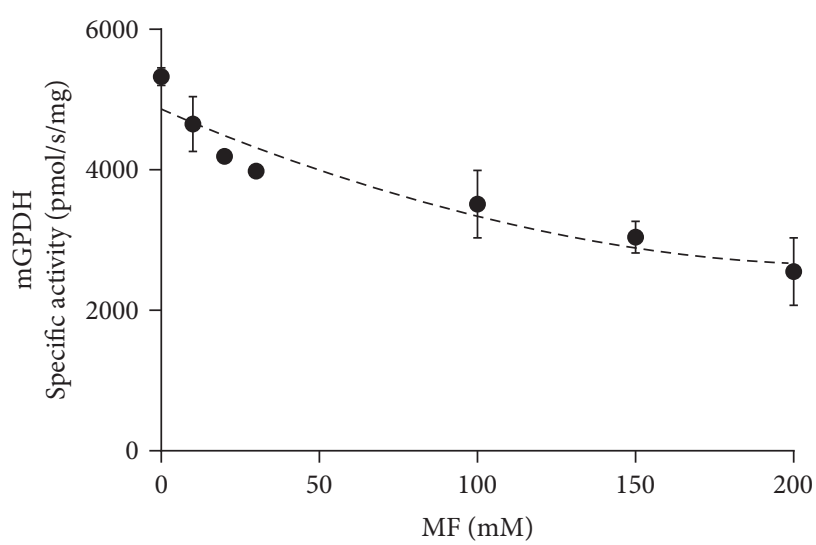

(c) Specific activity

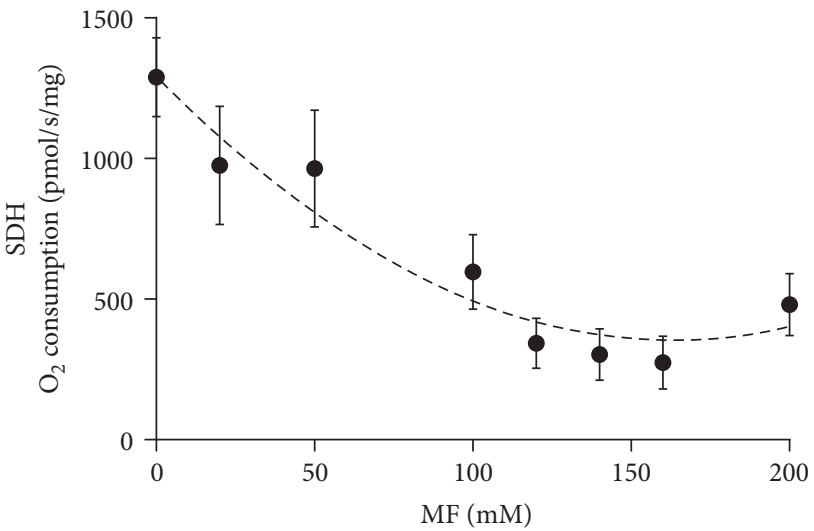

(e) $\mathrm{O}_{2}$ consumption

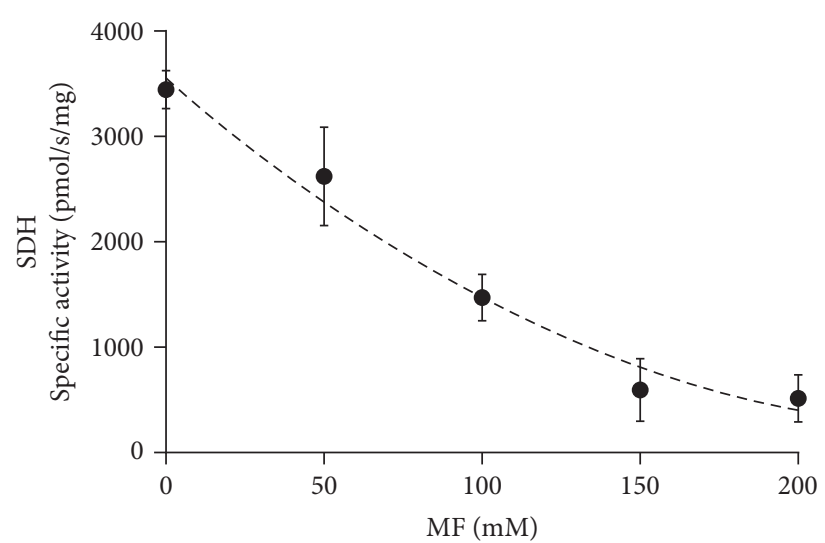

(b) Specific activity

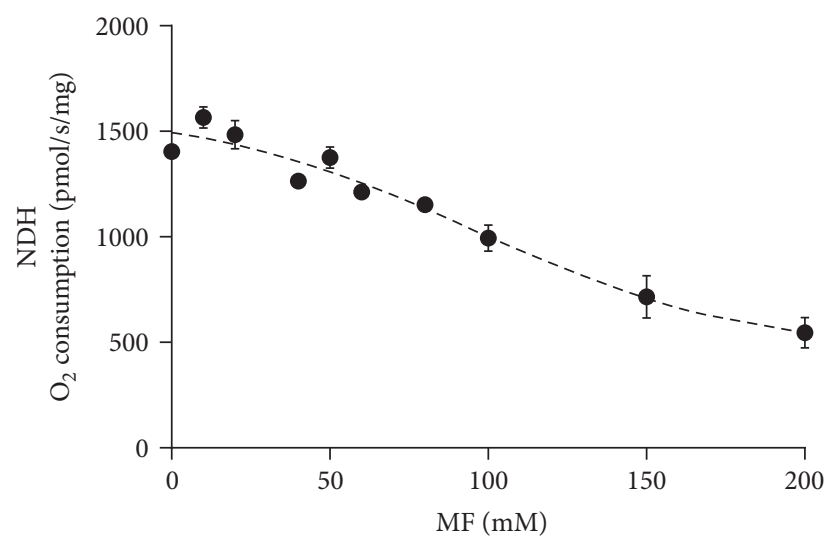

(d) $\mathrm{O}_{2}$ consumption

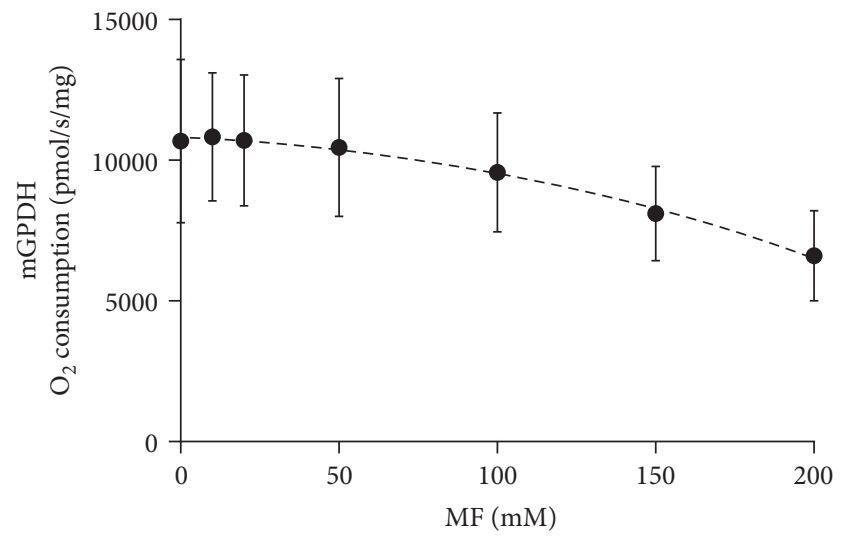

(f) $\mathrm{O}_{2}$ consumption

FIgURE 2: Respiratory chain dehydrogenase sensitivity to metformin titration. Specific enzyme activities (a, b, c) or oxygen consumption (d, e, f) of BAT mitochondria was titrated with $0-200 \mathrm{mM}$ metformin using $100 \mu \mathrm{M}$ NADH (a) or $10 \mathrm{mM}$ pyruvate plus $2 \mathrm{mM}$ malate (d), $10 \mathrm{mM}$ succinate (b, e), and $25 \mathrm{mM}$ (c) or $10 \mathrm{mM}$ glycerophosphate (f). Individual points represent means \pm SEM of at least three independent measurements.

120 and $150 \mathrm{mV}$ [23]. Since the reported values for metformin concentration inside tumors are in $1-10 \mu \mathrm{M}$ range [21], the actual concentration in respiring mitochondria could reach mM values, which is likely not sufficient for the inhibitory action on mitochondrial oxidative phosphorylation. Indeed, in this regard, it is important to note that two recent reports demonstrated higher tumor antiproliferative efficiency for mitochondrially targeted (through positive charge of conjugated TPP moiety) analogs of metformin $[46,47]$. However, metformin and its conjugated analogs accumulate in the mitochondrial matrix, where they can act on enzyme complexes facing this compartment, namely, $\mathrm{NDH}$ and SDH. The effect on mGPDH is more questionable, since this enzyme is located on the outer face of the inner membrane, facing the mitochondrial intermembrane space and does not span to the matrix [48]. One of the reports 




(a) Specific activity

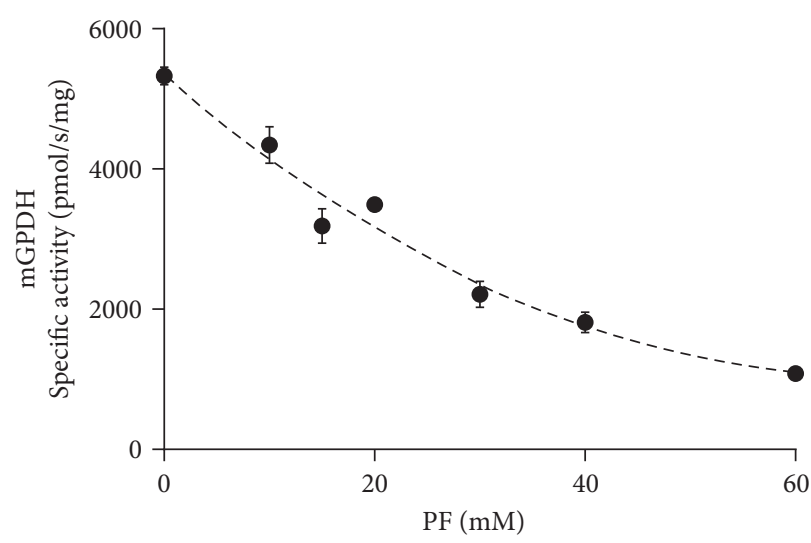

(c) Specific activity

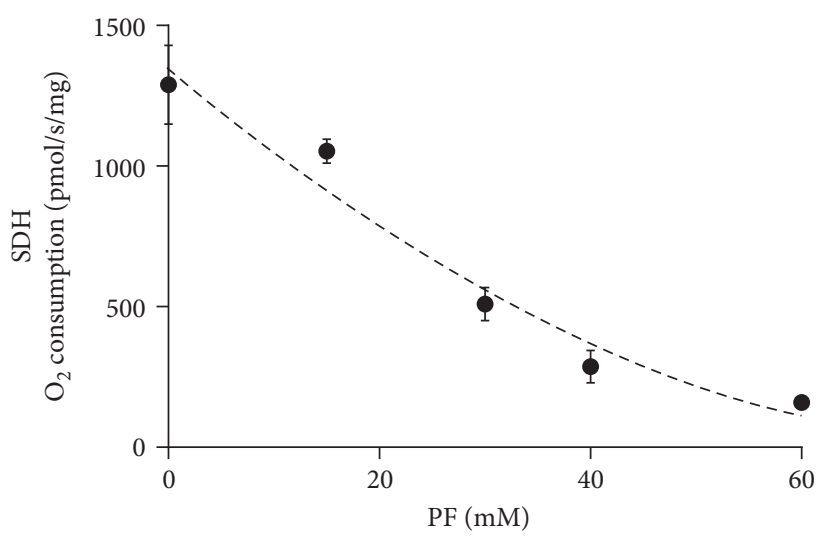

(e) $\mathrm{O}_{2}$ consumption

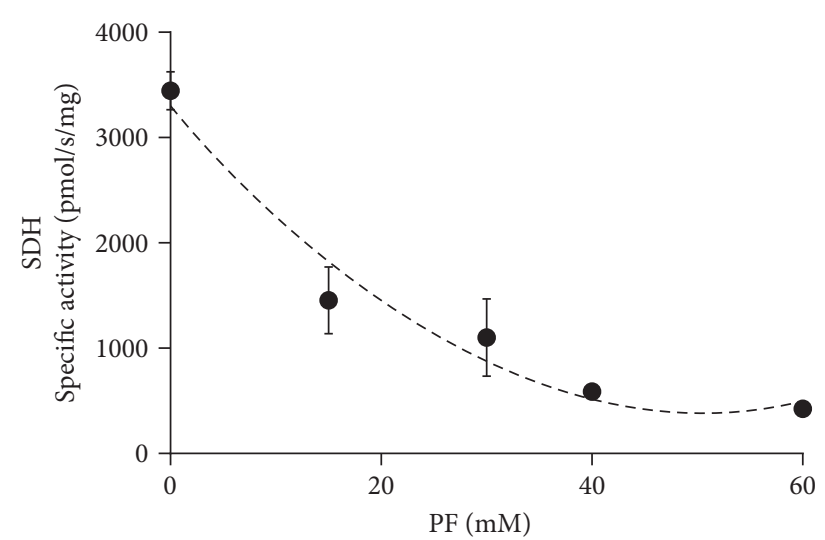

(b) Specific activity

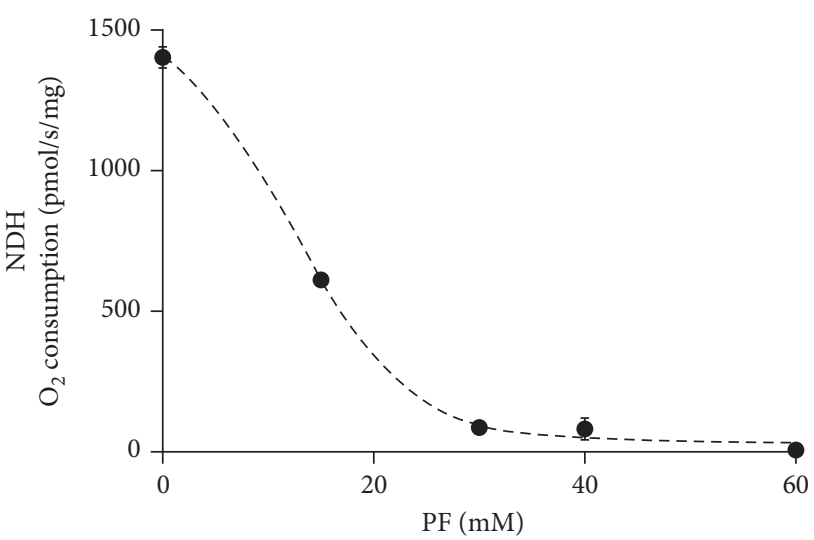

(d) $\mathrm{O}_{2}$ consumption

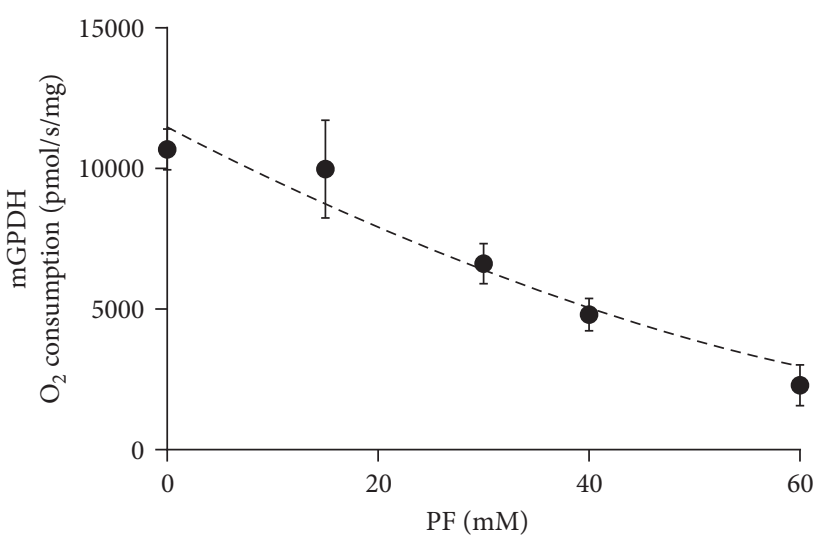

(f) $\mathrm{O}_{2}$ consumption

FIGURE 3: Respiratory chain dehydrogenases sensitivity to phenformin titration. Specific enzyme activities (a, b, c) or oxygen consumption $(\mathrm{d}, \mathrm{e}, \mathrm{f})$ of BAT mitochondria was titrated with $0-60 \mathrm{mM}$ phenformin using $100 \mu \mathrm{M}$ NADH (a) or $10 \mathrm{mM}$ pyruvate plus $2 \mathrm{mM}$ malate (d), $10 \mathrm{mM}$ succinate $(\mathrm{b}, \mathrm{e})$, and $25 \mathrm{mM}$ (c) or $10 \mathrm{mM}$ glycerophosphate (f). Individual points represent means \pm SEM of at least three independent measurements.

using mitochondrially targeted metformin analogs [46] reported also higher potency of that compound on GPdependent respiration, which would be in line with rather generalized nonspecific mode of action for example through the influencing of mitochondrial membrane properties.

3.2. Reactive Oxygen Species Production. Action of pharmacologically active compounds on suppression of cancer cell proliferation may not only be achieved by decreased flow of electrons through respiratory chain and associated impairment of aerobic ATP production. Another successful antiproliferative strategy may be to increase in reactive oxygen species (ROS) production and subsequent induction of apoptosis $[49,50]$. It was also proposed for biguanides that their primary antiproliferative effect is manifested through increase in ROS production $[21,23]$, which also holds true 


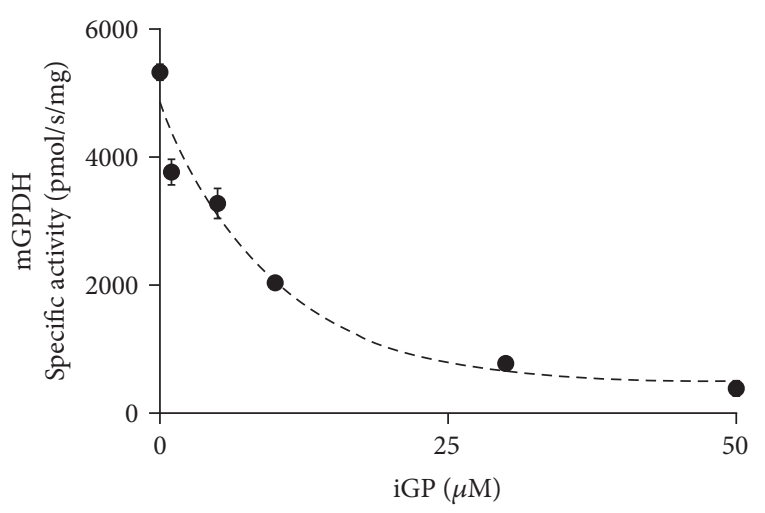

(a) Specific activity

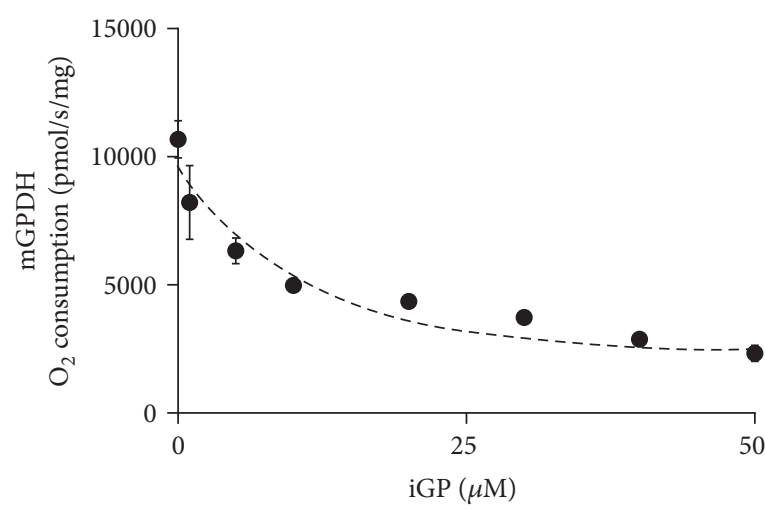

(c) $\mathrm{O}_{2}$ consumption

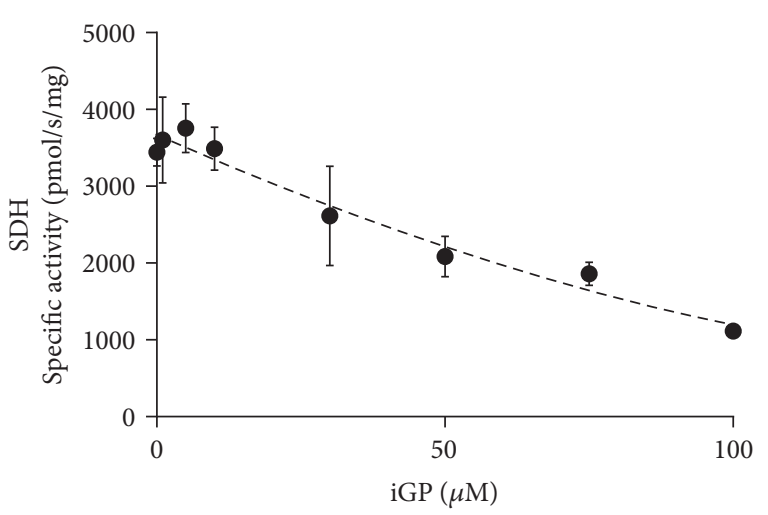

(b) Specific activity

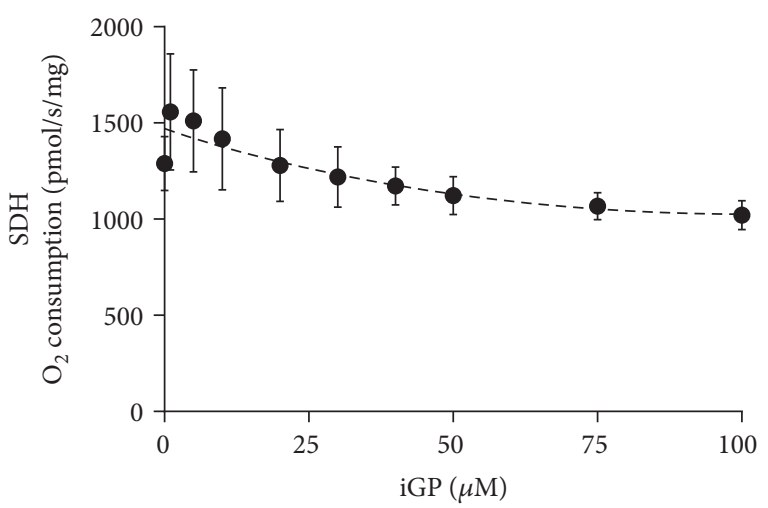

(d) $\mathrm{O}_{2}$ consumption

FIGURE 4: Comparison of iGP-1 effect on respiratory chain dehydrogenases mGPDH and SDH. Specific enzyme activities (a, b) or oxygen consumption (c, d) of BAT mitochondria was titrated with 0-100 $\mu \mathrm{M}$ iGP-1 using $25 \mathrm{mM}$ (a) or $10 \mathrm{mM}$ glycerophosphate (c) and $10 \mathrm{mM}$ succinate $(b, d)$. Individual points represent means \pm SEM of at least three independent measurements.

for the mitochondria-targeted analogs [51]. In this case, the mitochondrial ROS also interfered with redox signaling events. Mitochondrial respiratory chain contains numerous sites which may leak electrons to molecular oxygen and produce superoxide [27, 34, 35, 52-55]. The major superoxideproducing sites in mitochondrial respiratory chain were proposed to be NDH $[53,56]$, complex III $[53,57]$, mGPDH $[27,35]$, and, under certain circumstances, also SDH [34].

To distinguish sites in mitochondrial respiratory chain, where biguanides may induce electron leak, we followed the rates of ROS production (detected as $\mathrm{H}_{2} \mathrm{O}_{2}$ upon conversion by superoxide dismutase) in fresh mitochondria from BAT, where the respiratory chain is not reduced due to uncoupling by UCP1. First, using the established inhibitors of individual dehydrogenases and their respective substrates, we established ROS production pattern characteristic for each site in BAT mitochondria (Figure 5). As expected, also in BAT mitochondria, rotenone increased the rate of $\mathrm{H}_{2} \mathrm{O}_{2}$ production with $\mathrm{NADH}$-linked substrates (pyruvate and malate), indicative of ROS production from $\mathrm{I}_{\mathrm{F}}$ site (Figure 5(a)).

Using high concentrations of succinate $(10 \mathrm{mM})$, very low levels of ROS were produced in uncoupled state, which is in agreement with the previously published data [29] and this leak occurs at the Q site of SDH (Figure 5(b)). After GDP coupling, ROS were produced by the electron backflow at the $\mathrm{I}_{\mathrm{Q}}$ site of $\mathrm{NDH}$ (Figure 5(b)). Low levels of succinate led to pronounced increase in ROS production from flavin of $\mathrm{SDH}$ (inhibition of the Q site by atpenin A5, Figure 5(c)).

GP-dependent ROS production was quite high even when respiratory chain was not reduced and did not increase further after GDP addition, again in agreement with previously reported data $[37,58]$, and it was inhibited by mGPDH inhibitor iGP-1 (Figure 5(d)).

Compared to typical inhibitors, both metformin and phenformin induced dose-dependent increase in ROS production, but it seemed rather indiscriminative, as its pattern was highly similar for all substrates tested (Figures 5(e) and 5(f)). It suggests that these compounds do not bind directly to either flavin or ubiquinone-binding site of either of the dehydrogenases studied and that biguanides can affect mitochondria by different mechanisms, for example, they can influence membrane phospholipid environment.

\section{Conclusions}

Our data demonstrate that the inhibitory effect of biguanides on OXPHOS enzymes is rather pleiotropic including the previously reported inhibition of $\mathrm{NADH}$ and mGPDH dehydrogenases. Drug sensitivity of respiratory chain complexes in brown adipose tissue was comparable, with $\mathrm{IC}_{50}$ higher than $80 \mathrm{mM}$ in case of metformin or ranging from 20 to $30 \mathrm{mM}$ in case of the more potent phenformin. 


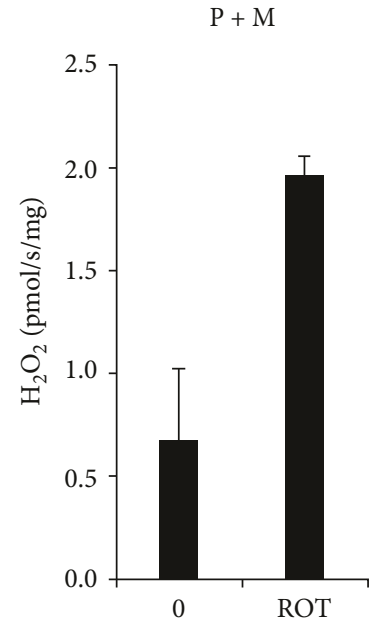

(a)
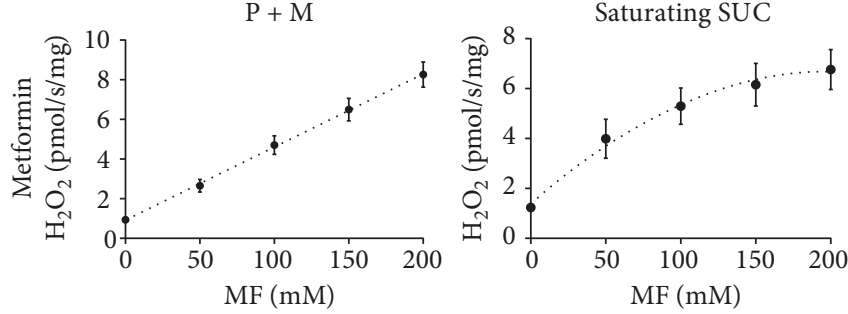

Physiological SUC

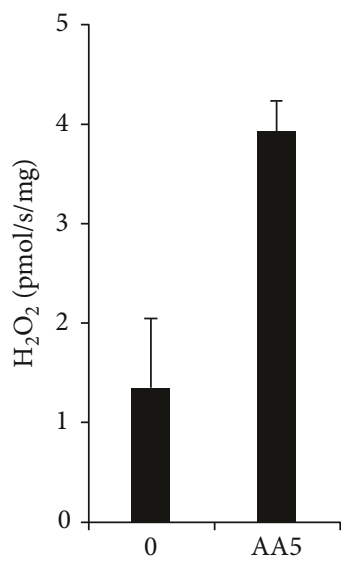

(c)
GP

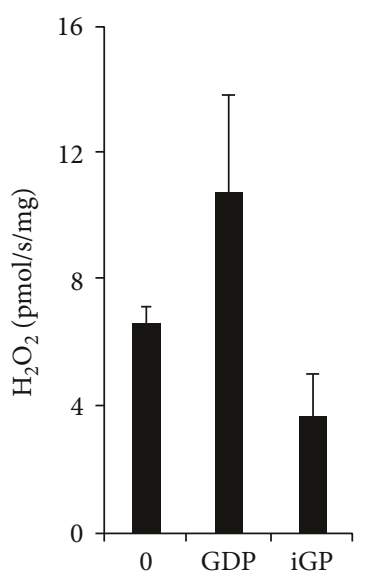

(d)
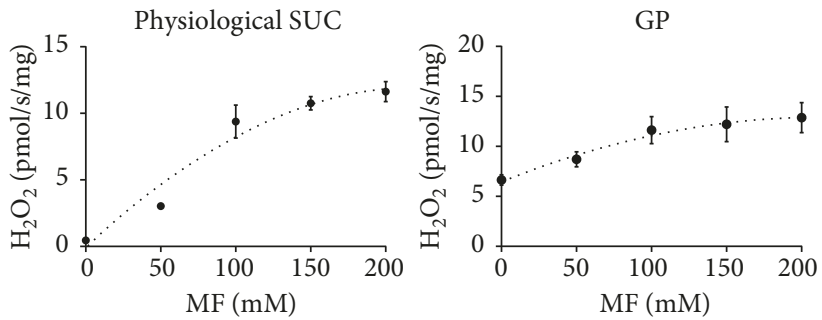

(e)
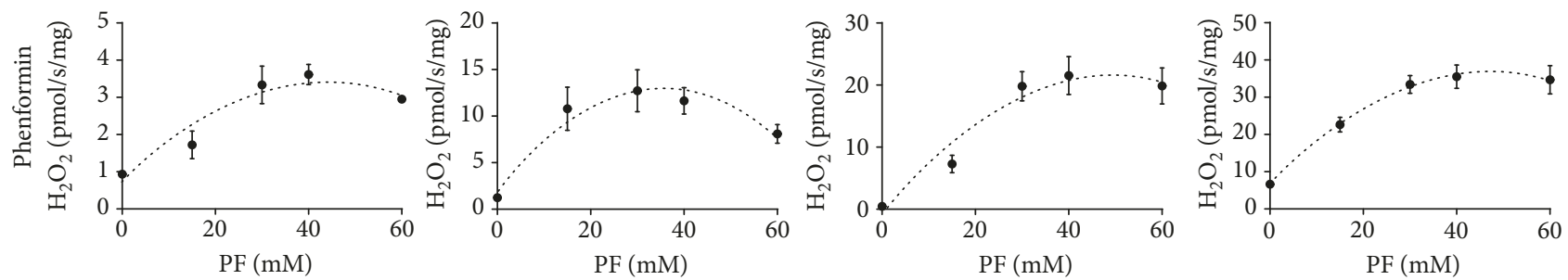

(f)

FIGURE 5: Effect of biguanides on reactive oxygen species (ROS) production compared to typical inhibitors. The rate of $\mathrm{H}_{2} \mathrm{O}_{2}$ generation was estimated by Amplex red assay. $\mathrm{H}_{2} \mathrm{O}_{2}$ production with (a) $10 \mathrm{mM}$ pyruvate and $2 \mathrm{mM}$ malate $(\mathrm{P}+\mathrm{M})$ with or without $1 \mu \mathrm{M}$ rotenone (ROT), (b) $10 \mathrm{mM}$ succinate (saturating SUC) with or without $0.5 \mu \mathrm{M}$ atpenin A5 (AA5) or $1 \mu \mathrm{M}$ rotenone, (c) $0.4 \mathrm{mM}$ succinate (physiological SUC) with or without $0.5 \mu \mathrm{M}$ atpenin A5, and (d) $10 \mathrm{mM}$ glycerophosphate (GP) with or without $100 \mu \mathrm{M}$ iGP-1 (iGP) were indicated; BAT mitochondria were coupled with $1 \mathrm{mM}$ guanosine diphosphate (GDP). (e) Titration of $\mathrm{H}_{2} \mathrm{O}_{2}$ production by biguanides metformin $(\mathrm{MF}, 0-200 \mathrm{mM})$ or $(\mathrm{f})$ phenformin $(\mathrm{PF}, 0-60 \mathrm{mM})$ using the same substrate concentrations as in respective experiments in $(\mathrm{a}-\mathrm{d})$. Each point is the mean \pm SEM of at least three independent measurements.
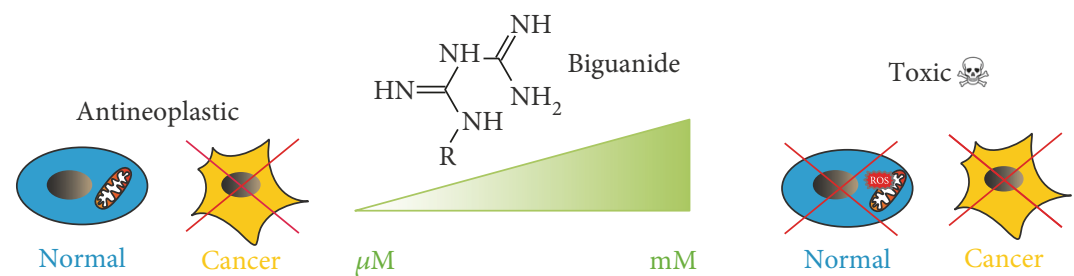

Figure 6: Proposed scheme of biguanide action. While at micromolar concentrations, biguanides confer antineoplastic action; at millimolar ones, they inhibit mitochondrial respiratory chain complexes and are toxic for all the cells. 
Moreover, these biguanide concentrations induce nonspecific increase of mitochondrial reactive oxygen species production. Our data suggest that biguanides do not bind to any specific sites on respiratory chain dehydrogenases and require high concentrations to be effective. Under these conditions, their effect on dehydrogenases remains therapeutically questionable. Indeed, phenformin use had to be discontinued due to induction of lactic acidosis in treated patients. As summarized in Figure 6, we propose that pharmacologically relevant concentrations of biguanides confer their antineoplastic effect through yet unidentified target in mitochondrial metabolism, different from the inhibition of individual dehydrogenases.

\section{Abbreviations}

$\begin{array}{ll}\text { BAT: } & \text { Brown adipose tissue } \\ \text { NDH: } & \text { NADH dehydrogenase } \\ \text { SDH: } & \text { Succinate dehydrogenase } \\ \text { mGPDH: } & \text { Mitochondrial glycerophosphate dehydrogenase } \\ \text { OXPHOS: } & \text { Oxidative phosphorylation } \\ \text { GDP: } & \text { Guanosine diphosphate } \\ \text { ROS: } & \text { Reactive oxygen species } \\ \text { MF: } & \text { Metformin } \\ \text { PF: } & \text { Phenformin } \\ \text { UCP1: } & \text { Uncoupling protein } 1 \\ \mathrm{I}_{\mathrm{Q}}: & \text { Coenzyme Q binding site of respiratory chain } \\ & \text { complex I } \\ \mathrm{I}_{\mathrm{F}}: & \text { Flavin site of respiratory chain complex I } \\ \mathrm{II}_{\mathrm{F}}: & \text { Flavin site of respiratory chain complex II. }\end{array}$

\section{Conflicts of Interest}

All authors declare that there is no conflict of interests.

\section{Acknowledgments}

This work was supported by the Grant Agency of the Czech Republic (16-12726S) and the Ministry of Education, Youth and Sports of the Czech Republic (ERC CZ: LL1204). Institutional support was provided through the Project RVO:67985823.

\section{References}

[1] E. Bosi, "Metformin-the gold standard in type 2 diabetes: what does the evidence tell us?," Diabetes, Obesity \& Metabolism, vol. 11, Supplement 2, pp. 3-8, 2009.

[2] R. K. Campbell, J. R. White Jr., and B. A. Saulie, "Metformin: a new oral biguanide," Clinical Therapeutics, vol. 18, no. 3, pp. 360-371, 1996.

[3] W. C. Knowler, E. Barrett-Connor, S. E. Fowler et al., "Reduction in the incidence of type 2 diabetes with lifestyle intervention or metformin," The New England Journal of Medicine, vol. 346, no. 6, pp. 393-403, 2002.

[4] R. A. Miller, Q. Chu, J. Xie, M. Foretz, B. Viollet, and M. J. Birnbaum, "Biguanides suppress hepatic glucagon signalling by decreasing production of cyclic AMP," Nature, vol. 494, no. 7436, pp. 256-260, 2013.
[5] Q. Wang, M. Zhang, G. Torres et al., "Metformin suppresses diabetes-accelerated atherosclerosis via the inhibition of Drp1-mediated mitochondrial fission," Diabetes, vol. 66, no. 1, pp. 193-205, 2017.

[6] K. Forslund, F. Hildebrand, T. Nielsen et al., "Disentangling type 2 diabetes and metformin treatment signatures in the human gut microbiota," Nature, vol. 528, no. 7581, pp. 262$266,2015$.

[7] A. K. Madiraju, D. M. Erion, Y. Rahimi et al., "Metformin suppresses gluconeogenesis by inhibiting mitochondrial glycerophosphate dehydrogenase," Nature, vol. 510, no. 7506, pp. 542-546, 2014.

[8] M. R. Owen, E. Doran, and A. P. Halestrap, "Evidence that metformin exerts its anti-diabetic effects through inhibition of complex 1 of the mitochondrial respiratory chain," The Biochemical Journal, vol. 348, no. 3, pp. 607-614, 2000.

[9] G. Zhou, R. Myers, Y. Li et al., "Role of AMP-activated protein kinase in mechanism of metformin action," The Journal of Clinical Investigation, vol. 108, no. 8, pp. 1167-1174, 2001.

[10] Z. Drahota, E. Palenickova, R. Endlicher et al., "Biguanides inhibit complex I, II and IV of rat liver mitochondria and modify their functional properties," Physiological Research, vol. 63 , no. 1, pp. 1-11, 2014.

[11] M. Foretz, B. Guigas, L. Bertrand, M. Pollak, and B. Viollet, "Metformin: from mechanisms of action to therapies," Cell Metabolism, vol. 20, no. 6, pp. 953-966, 2014.

[12] D. T. Eurich, S. R. Majumdar, F. A. McAlister, R. T. Tsuyuki, and J. A. Johnson, "Improved clinical outcomes associated with metformin in patients with diabetes and heart failure," Diabetes Care, vol. 28, no. 10, pp. 2345-2351, 2005.

[13] F. A. Masoudi, S. E. Inzucchi, Y. Wang, E. P. Havranek, J. M. Foody, and H. M. Krumholz, "Thiazolidinediones, metformin, and outcomes in older patients with diabetes and heart failure: an observational study," Circulation, vol. 111, no. 5, pp. 583-590, 2005.

[14] D. Sun and F. Yang, "Metformin improves cardiac function in mice with heart failure after myocardial infarction by regulating mitochondrial energy metabolism," Biochemical and Biophysical Research Communications, vol. 486, no. 2, pp. 329-335, 2017.

[15] J. Benes, L. Kazdova, Z. Drahota et al., "Effect of metformin therapy on cardiac function and survival in a volumeoverload model of heart failure in rats," Clinical Science, vol. 121, no. 1, pp. 29-41, 2011.

[16] A. Decensi, M. Puntoni, P. Goodwin et al., "Metformin and cancer risk in diabetic patients: a systematic review and meta-analysis," Cancer Prevention Research, vol. 3, no. 11, pp. 1451-1461, 2010.

[17] G. Libby, L. A. Donnelly, P. T. Donnan, D. R. Alessi, A. D. Morris, and J. M. Evans, "New users of metformin are at low risk of incident cancer: a cohort study among people with type 2 diabetes," Diabetes Care, vol. 32, no. 9, pp. 1620-1625, 2009.

[18] M. Pollak, "Potential applications for biguanides in oncology," The Journal of Clinical Investigation, vol. 123, no. 9, pp. 3693 3700, 2013.

[19] M. Pollak, "The insulin and insulin-like growth factor receptor family in neoplasia: an update," Nature Reviews Cancer, vol. 12, no. 3, pp. 159-169, 2012.

[20] T. Griss, E. E. Vincent, R. Egnatchik et al., "Metformin antagonizes cancer cell proliferation by suppressing mitochondrial- 
dependent biosynthesis," PLoS Biology, vol. 13, no. 12, article e1002309, 2015.

[21] X. Liu, I. L. Romero, L. M. Litchfield, E. Lengyel, and J. W. Locasale, "Metformin targets central carbon metabolism and reveals mitochondrial requirements in human cancers," Cell Metabolism, vol. 24, no. 5, pp. 728-739, 2016.

[22] M. Y. El-Mir, V. Nogueira, E. Fontaine, N. Averet, M. Rigoulet, and X. Leverve, "Dimethylbiguanide inhibits cell respiration via an indirect effect targeted on the respiratory chain complex I," The Journal of Biological Chemistry, vol. 275, no. 1, pp. 223228, 2000.

[23] H. R. Bridges, A. J. Jones, M. N. Pollak, and J. Hirst, "Effects of metformin and other biguanides on oxidative phosphorylation in mitochondria," The Biochemical Journal, vol. 462, no. 3, pp. 475-487, 2014.

[24] W. W. Wheaton, S. E. Weinberg, R. B. Hamanaka et al., "Metformin inhibits mitochondrial complex I of cancer cells to reduce tumorigenesis," eLife, vol. 3, article e02242, 2014.

[25] B. Viollet, B. Guigas, N. Sanz Garcia, J. Leclerc, M. Foretz, and F. Andreelli, "Cellular and molecular mechanisms of metformin: an overview," Clinical Science, vol. 122, no. 6, pp. 253-270, 2012.

[26] X. Liu, R. R. Chhipa, S. Pooya et al., "Discrete mechanisms of mTOR and cell cycle regulation by AMPK agonists independent of AMPK," Proceedings of the National Academy of Sciences of the United States of America, vol. 111, no. 4, pp. E435-E444, 2014.

[27] T. Mracek, E. Holzerova, Z. Drahota et al., "ROS generation and multiple forms of mammalian mitochondrial glycerol-3phosphate dehydrogenase," Biochimica et Biophysica Acta (BBA) - Bioenergetics, vol. 1837, no. 1, pp. 98-111, 2014.

[28] A. P. Kudin, N. Y. Bimpong-Buta, S. Vielhaber, C. E. Elger, and W. S. Kunz, "Characterization of superoxide-producing sites in isolated brain mitochondria," The Journal of Biological Chemistry, vol. 279, no. 6, pp. 4127-4135, 2004.

[29] C. L. Quinlan, J. R. Treberg, I. V. Perevoshchikova, A. L. Orr, and M. D. Brand, "Native rates of superoxide production from multiple sites in isolated mitochondria measured using endogenous reporters," Free Radical Biology and Medicine, vol. 53, no. 9, pp. 1807-1817, 2012.

[30] S. S. Korshunov, V. P. Skulachev, and A. A. Starkov, "High protonic potential actuates a mechanism of production of reactive oxygen species in mitochondria," FEBS Letters, vol. 416, no. 1, pp. 15-18, 1997.

[31] A. J. Lambert and M. D. Brand, "Superoxide production by NADH: ubiquinone oxidoreductase (complex I) depends on the $\mathrm{pH}$ gradient across the mitochondrial inner membrane," The Biochemical Journal, vol. 382, Part 2, pp. 511-517, 2004.

[32] A. Herrero and G. Barja, "Sites and mechanisms responsible for the low rate of free radical production of heart mitochondria in the long-lived pigeon," Mechanisms of Ageing and Development, vol. 98, no. 2, pp. 95-111, 1997.

[33] J. Hirst, M. S. King, and K. R. Pryde, "The production of reactive oxygen species by complex I," Biochemical Society Transactions, vol. 36, Part 5, pp. 976-980, 2008.

[34] C. L. Quinlan, A. L. Orr, I. V. Perevoshchikova, J. R. Treberg, B. A. Ackrell, and M. D. Brand, "Mitochondrial complex II can generate reactive oxygen species at high rates in both the forward and reverse reactions," The Journal of Biological Chemistry, vol. 287, no. 32, pp. 27255-27264, 2012.
[35] Z. Drahota, S. K. Chowdhury, D. Floryk et al., "Glycerophosphate-dependent hydrogen peroxide production by brown adipose tissue mitochondria and its activation by ferricyanide," Journal of Bioenergetics and Biomembranes, vol. 34, no. 2, pp. 105-113, 2002.

[36] T. Mracek, A. Pecinova, M. Vrbacky, Z. Drahota, and J. Houstek, "High efficiency of ROS production by glycerophosphate dehydrogenase in mammalian mitochondria," Archives of Biochemistry and Biophysics, vol. 481, no. 1, pp. 30-36, 2009.

[37] M. Vrbacky, Z. Drahota, T. Mracek et al., "Respiratory chain components involved in the glycerophosphate dehydrogenase-dependent ROS production by brown adipose tissue mitochondria," Biochimica et Biophysica Acta (BBA) Bioenergetics, vol. 1767, no. 7, pp. 989-997, 2007.

[38] B. Cannon and O. Lindberg, "Mitochondria from brown adipose tissue: isolation and properties," Methods in Enzymology, vol. 55, pp. 65-78, 1979.

[39] A. Labajova, A. Vojtiskova, P. Krivakova, J. Kofranek, Z. Drahota, and J. Houstek, "Evaluation of mitochondrial membrane potential using a computerized device with a tetraphenylphosphonium-selective electrode," Analytical Biochemistry, vol. 353, no. 1, pp. 37-42, 2006.

[40] A. Pecinova, Z. Drahota, H. Nuskova, P. Pecina, and J. Houstek, "Evaluation of basic mitochondrial functions using rat tissue homogenates," Mitochondrion, vol. 11, no. 5, pp. 722-728, 2011.

[41] H. Schagger and G. von Jagow, "Tricine-sodium dodecyl sulfate-polyacrylamide gel electrophoresis for the separation of proteins in the range from 1 to $100 \mathrm{kDa}$," Analytical Biochemistry, vol. 166, no. 2, pp. 368-379, 1987.

[42] T. Mracek, P. Jesina, P. Krivakova et al., "Time-course of hormonal induction of mitochondrial glycerophosphate dehydrogenase biogenesis in rat liver," Biochimica et Biophysica Acta (BBA) - General Subjects, vol. 1726, no. 2, pp. 217-223, 2005.

[43] H. Miyadera, K. Shiomi, H. Ui et al., "Atpenins, potent and specific inhibitors of mitochondrial complex II (succinateubiquinone oxidoreductase)," Proceedings of the National Academy of Sciences of the United States of America, vol. 100, no. 2, pp. 473-477, 2003.

[44] A. L. Orr, D. Ashok, M. R. Sarantos et al., "Novel inhibitors of mitochondrial sn-glycerol 3-phosphate dehydrogenase," PLoS One, vol. 9, no. 2, article e89938, 2014.

[45] J. Houstek, B. Cannon, and O. Lindberg, "Glycerol-3phosphate shuttle and its function in intermediary metabolism of hamster brown-adipose tissue," European Journal of Biochemistry, vol. 54, no. 1, pp. 11-18, 1975.

[46] S. Boukalova, J. Stursa, L. Werner et al., "Mitochondrial targeting of metformin enhances its activity against pancreatic cancer," Molecular Cancer Therapeutics, vol. 15, no. 12, pp. 2875-2886, 2016.

[47] G. Cheng, J. Zielonka, O. Ouari et al., "Mitochondria-targeted analogues of metformin exhibit enhanced antiproliferative and radiosensitizing effects in pancreatic cancer cells," Cancer Research, vol. 76, no. 13, pp. 3904-3915, 2016.

[48] T. Mracek, Z. Drahota, and J. Houstek, "The function and the role of the mitochondrial glycerol-3-phosphate dehydrogenase in mammalian tissues," Biochimica et Biophysica Acta (BBA) - Bioenergetics, vol. 1827, no. 3, pp. 401-410, 2013. 
[49] K. Kluckova, M. Sticha, J. Cerny et al., "Ubiquinone-binding site mutagenesis reveals the role of mitochondrial complex II in cell death initiation," Cell Death \& Disease, vol. 6, article e1749, 2015.

[50] J. Rohlena, L. F. Dong, K. Kluckova et al., "Mitochondrially targeted alpha-tocopheryl succinate is antiangiogenic: potential benefit against tumor angiogenesis but caution against wound healing," Antioxidants \& Redox Signaling, vol. 15, no. 12, pp. 2923-2935, 2011.

[51] B. Kalyanaraman, G. Cheng, M. Hardy et al., "Modified metformin as a more potent anticancer drug: mitochondrial inhibition, redox signaling, antiproliferative effects and future EPR studies," Cell Biochemistry and Biophysics, 2017.

[52] E. Cadenas and K. J. Davies, "Mitochondrial free radical generation, oxidative stress, and aging," Free Radical Biology and Medicine, vol. 29, no. 3-4, pp. 222-230, 2000.

[53] Q. Chen, E. J. Vazquez, S. Moghaddas, C. L. Hoppel, and E. J. Lesnefsky, "Production of reactive oxygen species by mitochondria: central role of complex III," The Journal of Biological Chemistry, vol. 278, no. 38, pp. 36027-36031, 2003.

[54] P. Schonfeld and L. Wojtczak, "Brown adipose tissue mitochondria oxidizing fatty acids generate high levels of reactive oxygen species irrespective of the uncoupling protein-1 activity state," Biochimica et Biophysica Acta (BBA) - Bioenergetics, vol. 1817, no. 3, pp. 410-418, 2012.

[55] L. Tretter and V. Adam-Vizi, "Generation of reactive oxygen species in the reaction catalyzed by alpha-ketoglutarate dehydrogenase," The Journal of Neuroscience, vol. 24, no. 36, pp. 7771-7778, 2004.

[56] L. Kussmaul and J. Hirst, "The mechanism of superoxide production by NADH:ubiquinone oxidoreductase (complex I) from bovine heart mitochondria," Proceedings of the National Academy of Sciences of the United States of America, vol. 103, no. 20, pp. 7607-7612, 2006.

[57] C. L. Quinlan, A. A. Gerencser, J. R. Treberg, and M. D. Brand, "The mechanism of superoxide production by the antimycininhibited mitochondrial Q-cycle," The Journal of Biological Chemistry, vol. 286, no. 36, pp. 31361-31372, 2011.

[58] I. G. Shabalina, M. Vrbacky, A. Pecinova et al., "ROS production in brown adipose tissue mitochondria: the question of UCP1-dependence," Biochimica et Biophysica Acta (BBA) Bioenergetics, vol. 1837, no. 12, pp. 2017-2030, 2014. 


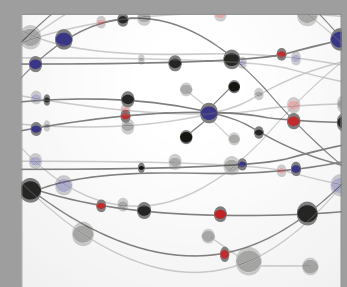

The Scientific World Journal
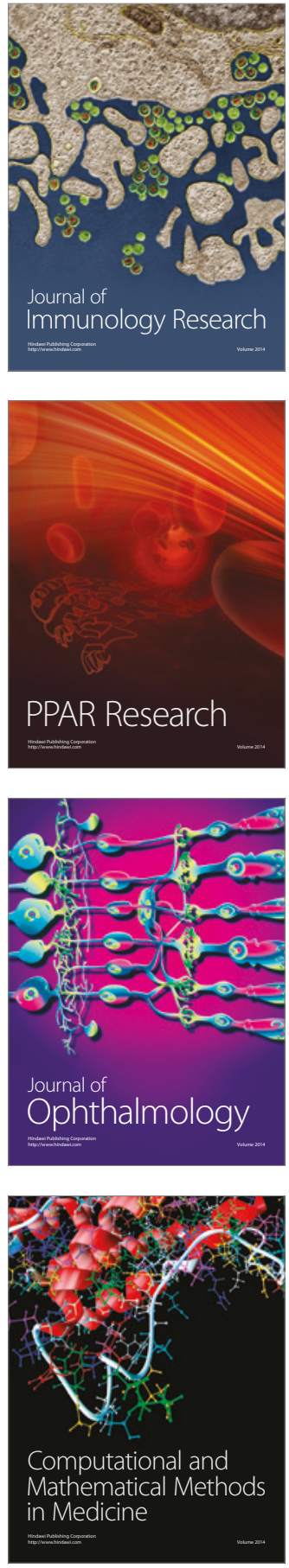

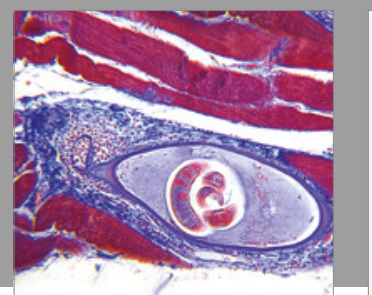

Gastroenterology Research and Practice
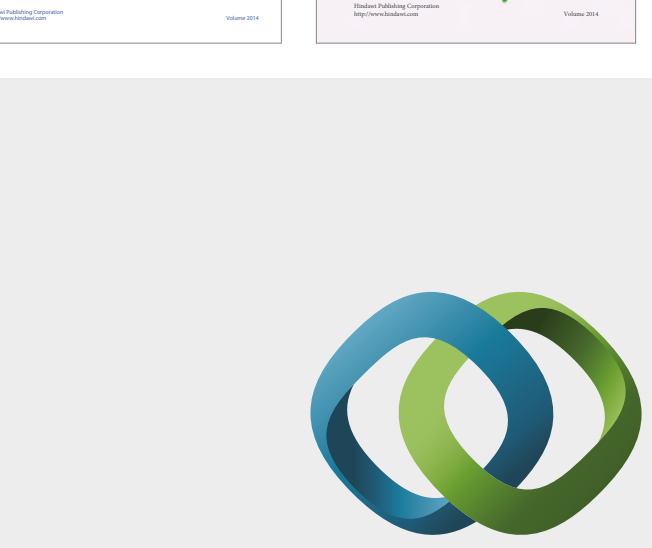

\section{Hindawi}

Submit your manuscripts at

https://www.hindawi.com
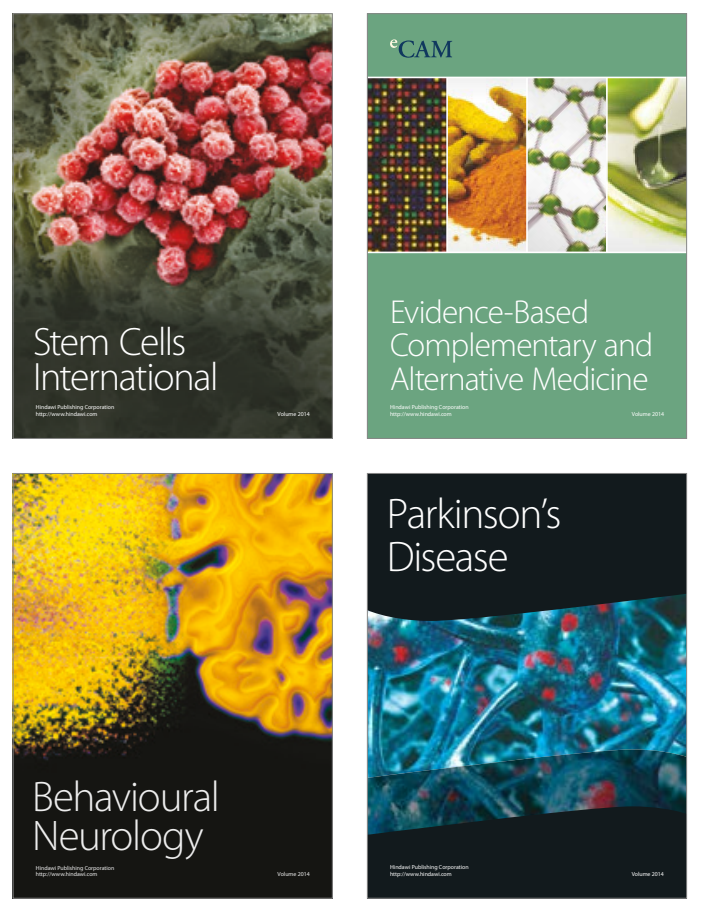
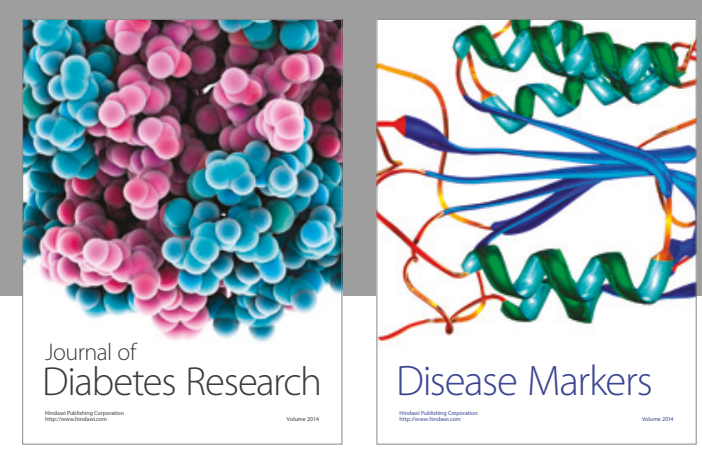

Disease Markers
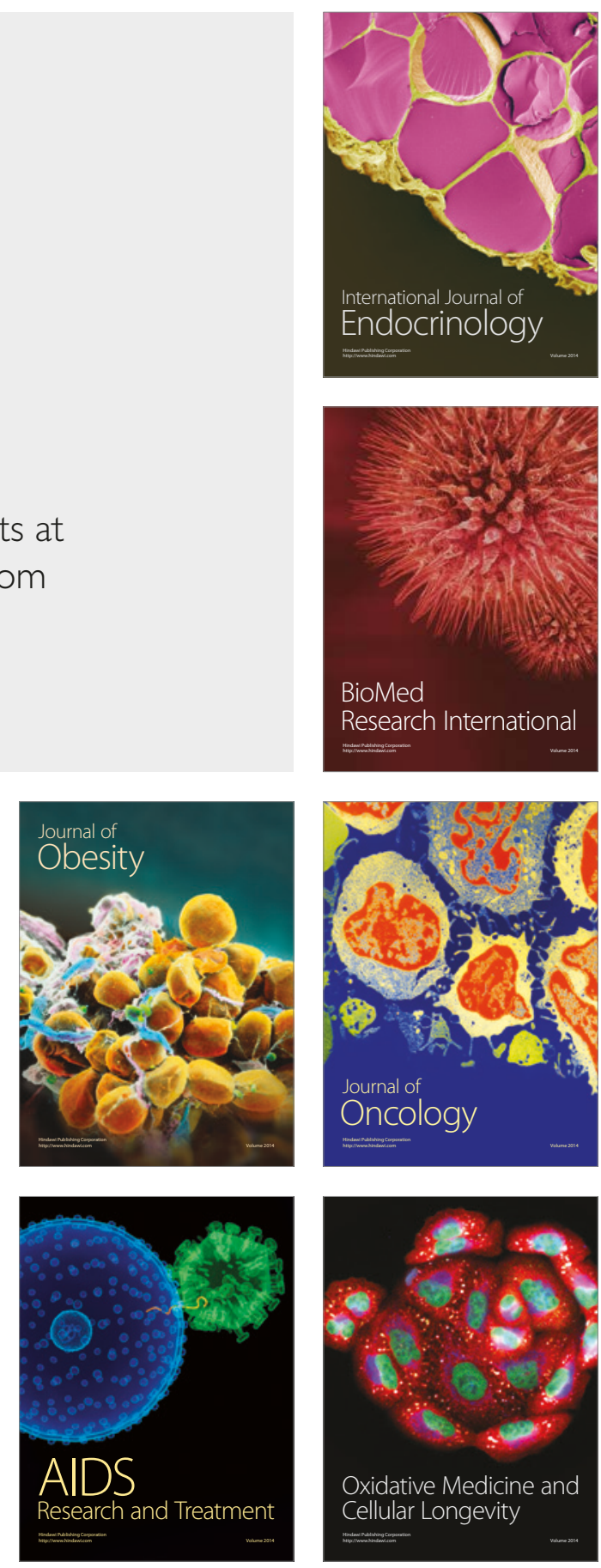